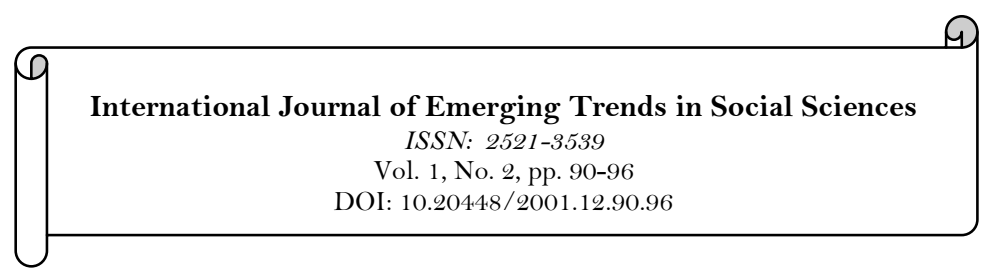

\title{
Ideology and Distortions of the Entrepreneurial Concept. The Results of Conflict in Organizational Culture
}

\author{
Petro Vlasov ${ }^{1}$ \\ Anna Kiseleva ${ }^{2}$ \\ 1,2Institute of Applied Psychology “Humanitarian center” Chernyshevskaya Street, 34, Kharkov 61002, Ukraine.
}

\begin{tabular}{|c|c|}
\hline Abstract & \\
\hline $\begin{array}{l}\text { Organizations constantly exist in a process of sense-making, } \\
\text { interpretation and sense-transfer. It is initiated by various centers } \\
\text { (top-managers, external organizational environment, clients). The } \\
\text { initial concept of organization is being distorted repeatedly. The } \\
\text { initiator's initial concept loses its symbolic value and can't be } \\
\text { realized. Managers avoid to produce and transmit meanings, refuse } \\
\text { to reduce uncertainty. They reduce the pressure of responsibility } \\
\text { through ideology, creating the discourse that justifies such behavior. } \\
\text { The function of ideology is to simplify, depersonify and to reduce the } \\
\text { need for productive tension. They start to compete with initiator for } \\
\text { the meaning, creating organizational myth. Consequently, official } \\
\text { organizational policy must first of all be oriented towards } \\
\text { transformation of ideology into methodology of solving } \\
\text { organizational problems. }\end{array}$ & $\begin{array}{l}\text { Licensed: } \\
\text { This work is licensed under a } \\
\text { Creative Commons Attribution } \\
\text { 4.0 License. } \\
\text { Publisher: } \\
\text { Scientific Publishing Institute }\end{array}$ \\
\hline
\end{tabular}

\section{Problem Setting}

Organizations constantly exist in a process of sense-making, interpretation and sense-transfer. This process is initiated by various centers - by top-managers, external organizational environment, clients. Thus the initial concept of organization is being distorted repeatedly. From the very beginning, the initiator, by creating the concept of organization, sets a certain amount of meanings that are significant, in his view, for the survival of organization. The meaning of organization changes depending on a stage in its life circle. Indeed, an organization at a stage of its very creation is characterized by flexibility, new way of thinking and dynamics. Then management and personnel "stabilize" the situation of development and create their own discourse/linguistic ideology which distorts (informational corruption) or maintains the concept and attaining organizational goals. That is why we have decided to analyze the top-managers' stylistic features in reinterpretation/corruption of a human-initiator's concept which lead to the conflicts in organizational culture. (Laclau \& Mouff, 1985)

\section{Basic Theses}

The concept of organization is a "value-cognitive-action" pattern that organizes and initiates organizational performance.

The concept is an anticipated system of initiator's meanings. It passes through certain stages of objectification at all hierarchical levels - morphology, axiology, praxiology, ontology, gnoseology - through the resource relationships with consumers - with partners, suppliers, clients, technological possibilities. In such way it transforms into a conception, project and technology of organizational changes Figure 2.

In a transitional environment initiator and concept exert much greater influence upon the production of organizations that the environment does. The concept orders external environment, brings a certain meaning to it and, by virtue of this, creates its own environment - favorable conditions for the creation of organizations. So in a process of the realization of ideas people create their own reality. It literally implies that people make the ideas real. 


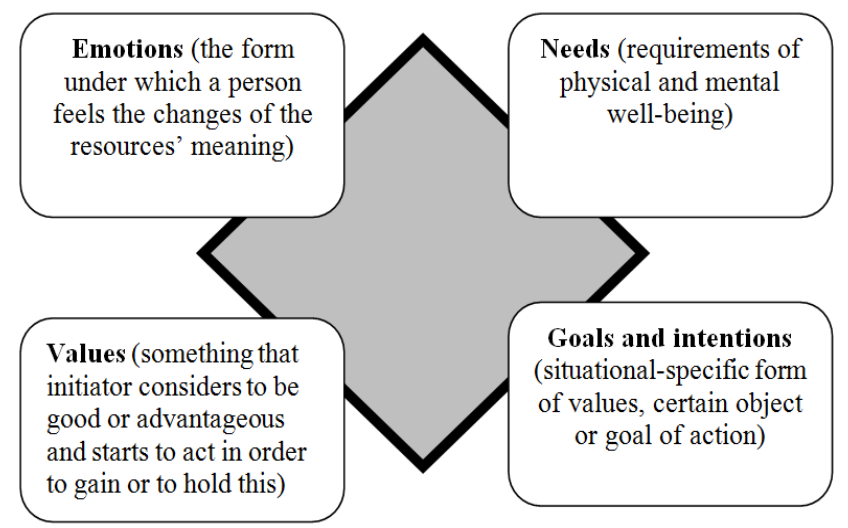

Figure-1. The structure of organizational concept.

Environment. "Man-initiator" is a system-forming factor of the external organizational environment, and he exerts an ultimate influence upon the initial choice of the environmental parameters. The process of subjective evaluation takes place in a meta-context of value-based, cultural norms that are determined by the chronology of the development of socio-economic system. They condition "conventional" structure of the surrounding world and individual descriptive thesaurus of a concept.

Uncertainty is an important characteristic of a transitional environment. Subjective uncertainty can be represented at the level of morphology - elements, links; at the level of ontology - in causes and effects; and praxiology - ways of coping, managing and reacting; and axiology - the level of meanings, goals and values; and gnoseology - ways of exploring, measuring and describing. Subjective uncertainty at these levels has different architectonics (the degree of representation and intensity). And this, in its turn, leads to a completely different reflection of subjective uncertainty in a subject activity.

Systemic parametric conception of an environment overcomes objective and subjective specificity and includes parameters of meta-context, that is special environmental conditions that can't be reduced to a single cases, products and technologies. This is: power-intensity - potentiality (power) of influence of the meaningful environmental parameters. And, in general, in determines the essence of the process of formation of valuebased relation (axiology) of environment, independently of modality; changeability - the degree of dispersion, the area of possible conditions of the environment that are meaningful for initiator or organization; dynamism - characterizes the speed of transitional processes from one environmental state into another.

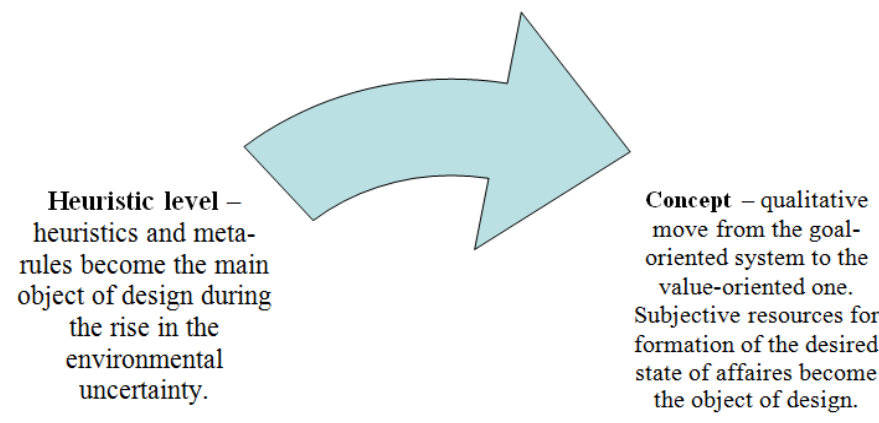

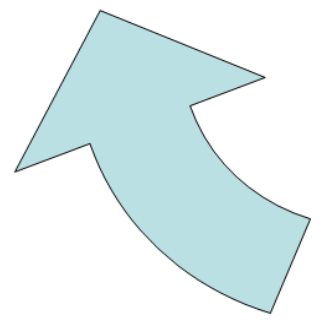

Normative level -

norms, rules and standards, become the main object of design under determined conditions

Concept - qualitative oriented system to the value-oriented one. ubjective resources for tate of affaires become the object of design.

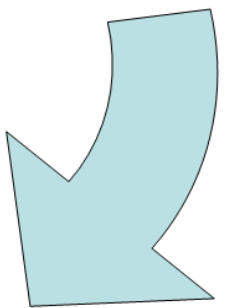

Figure-2. Ontology of the concept in a context of environmental uncertainty.

Under the conditions of transitional environment, what was intended is being changed many times in interaction with environment. That is why the concept that has been formed can differ significantly during its implementation from the initial one. 
In a situation of transitional economy external and internal organizational environment changes. Traditionally its basic differences are considered to be: uncertainty as a changeability and lack of predictability in conditions, tasks and demands of the work. It demands to regularly and radically change the participants' relations and actions.

The rise of environmental complexity (uncertainty) sets additional requirements towards organization's possibility to relevantly change external and internal processes and to maintain the goal at the same time. Under such conditions organizations feel much more pressure to additionally determine the conditions and to test their hypotheses directly in the process of changes, that is to solve open-ended tasks.

At the one hand, transitional environment possesses a redundant changeability of conditions (of the "old", "new" and "emergent" environment), high speed of transformation from one state into another. On the other hand, it changes both objective and subjective significance of the most important environmental segments which directly ensure the vital functions both of an individual person and the society as a whole. As a result, transitional environment frustrates the use of individual and organizational ways of vital activity that have been formed earlier. This implies that subjective conception of environment which is adequate today, may not fit the requirements of environment in a near-term outlook. Thus, uncertainty is an important characteristics of transitional environment.

Organization has to overcome the uncertainty (to produce clarity and exactness in the description of reality) of the external and internal environment. It must produce, interpret and transmit meanings in order to adequately secure its place in space, and takes actions to reduce the uncertainty.

We suppose that organization is a specific open socio-economic environment which is formed in order to attain certain complex effect (the realization of a concept) in the process of interaction between the initiator and external environment (of a life cycle) through the continuous selection of the necessary elements (of various nature) and through the specific way of ordering the structure and relations between them in the process of interaction with external organizational environment.

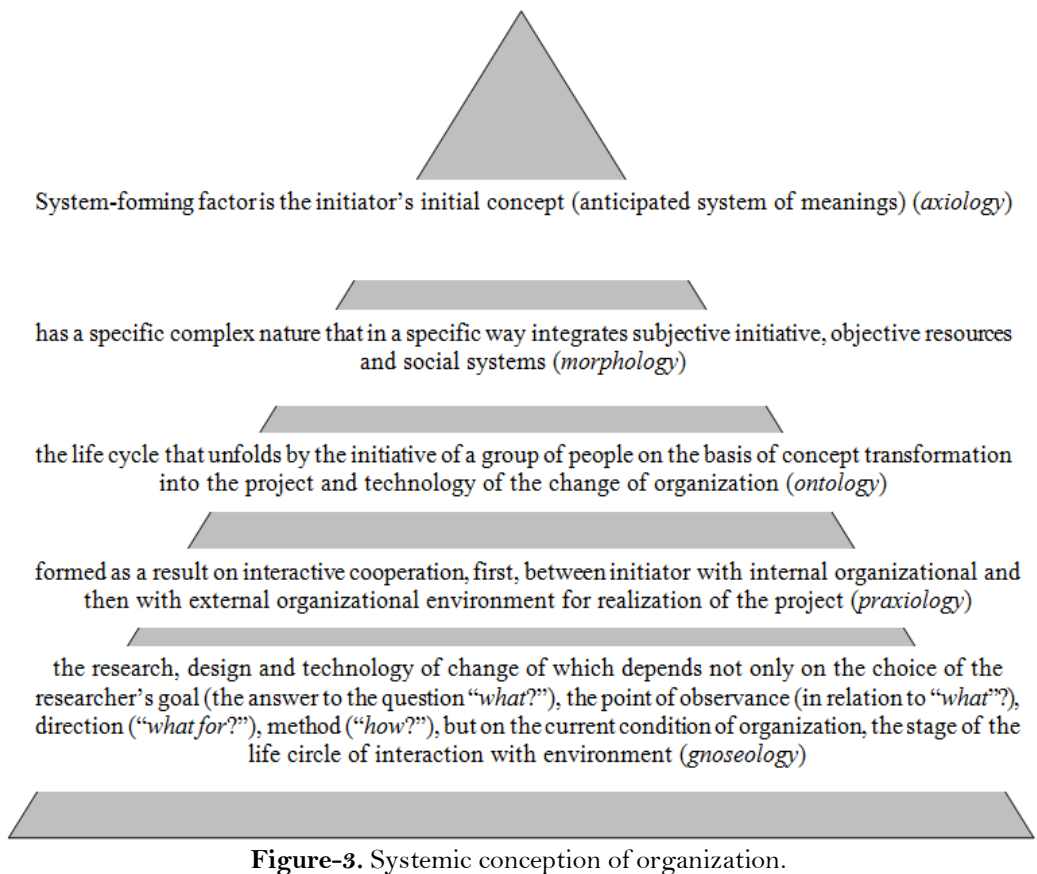

Figure-3. Systemic conception of organization.

There is a gap between the fact of reality and a person's ability to comprehend and to interpret it. Such "semantic vacuum" is a constant and natural man's "habitat" in which he manages to orient and adapt. The mechanisms of reducing the semantic vacuum are often called "coping strategies", strategies of reducing uncertainty (Choulioraki \& Fairclough, 1999) the process of sensemaking (Zankovsky, 2011) and producing of inferences (Zankovsky, 2011).

Reducing uncertainty and producing of meanings mostly take place in "language" (linguistic) dimension. To use the language means to take part in a social process of constructing a specific reality. And we make it with the help of producing of meanings.

Discourse. In a process of sensemaking participants of organization choose the meanings from the alternatives. Thus, the most frequent ones become the most socially accepted and are fixed by certain segments of reality. As a result of a series choices of meanings, participants of organization form what is called "discourse" which eventually sets the meanings of reality and produces social and organizational reality.

Thus, internal discourse is being formed, it starts to set the content, its elements, to create the differences between the objects, to nominate and attribute meanings in organizational reality. Organizational communication may be compared with discourse - a complex of texts produced by the workers. This discourse constitutes the culture of the company, the rituals of interaction between participants, organizational climate (Weik, 2001). In 
everyday communication through the organizational discourse organizational changes take place. Their main instrument is description, attribution, evaluation and interpretation.

Discourse is a form of social practice which simultaneously creates social world and is created through other social practices. Discourse is an important form of social practice which not only represents but changes knowledge, identities and social relationships including the power relations (Fairclough).

“Sediment discourses (Vlasov, 2004) are the rules, norms, relations, power distribution, organization's image and taken for granted, implicit knowledge, symbolic capital of organization and organizational beliefs.

Various discourses - each of which represents a certain way of communication and understanding of social world - are involved into a constant struggle for gaining superiority. They "strive" to fix their meaning. The superiority of a discourse can be understood as a prevailing of one certain point of view. Thus an ideology forms in a company - the priority of a certain organizational group's point of view. Then free exchange of meanings and the process of sesnsemaking become closed, meanings are not renewed. Consequently, informational distortions take place, closedness towards external environment forms, the company loses its adaptation. This leads to the situation where initially set meanings, especially the one of initiator, is diffused and loses the reality. Ideology, according to Fairclough, is a "meaning at the service of power"(Jorgensen \& Phillips, n.d) To be more specific, he understands ideology as certain constructions of meanings which favors producing, reproducing and transforming of power relations. The problem of meaning representation (or ideologization) arises: how representative and valid are the meanings which are created by the participants of organization as a descriptive instrument? What descriptive power do they possess? Do they describe the state of affairs which exists in organization? Does this description allow the initiator to realize his concept? These questions determine the main research problem.

\section{Method}

Sample - 92 top-managers of 9 manufacturing and commercial companies numbering 50-1500 workers.

Method. We have offered to the group of top-managers to interpret the case "Sabotage of new orders". We have chosen interpretative approach since it allows to a maximum degree research the individual features in describing the reality. Interpretation reflects the author's personal position and his vision of the right order of affairs. All the narratives were fixed with the help of dictating machine. We have chosen discourse-analysis as a method of data processing because it is directly intended for the "disclosure" of the established ways of distribution of power, domination, ideology and roles (Fairclough). In order to process the narratives, we used the criteria that are conventional for discourse-analysis (Kiseleva, 2004). As a result, we have reconstructed general discourse out of the narratives of interpretations. And then, on the basis of semantic proximity, we have singled out several kinds of discourses that reflect discourse-order of behavior in organization. For the evaluation of productivity or distortions we applied hierarchical structure of sensemaking resulted in a series of empirical researches (Schank, 1985). We think that that this hierarchy describes the process of sensemaking in organization fully enough. We will apply it for processing an interpreting the results of our empirical research. We have adapted the model of interaction "human-text" as a model of sensemaking. We have chosen narrative text about certain event (similar to a case). For the purpose of data gathering, we have adapted the method of intertextual questions: we stimulated the respondents to ask questions to each sentence so that they could exactly understand the meaning of the text. We supposed that the question is an activity targeted at reducing uncertainty and understanding of the meaning. As a result, we have discovered hierarchical structure of sensemaking:

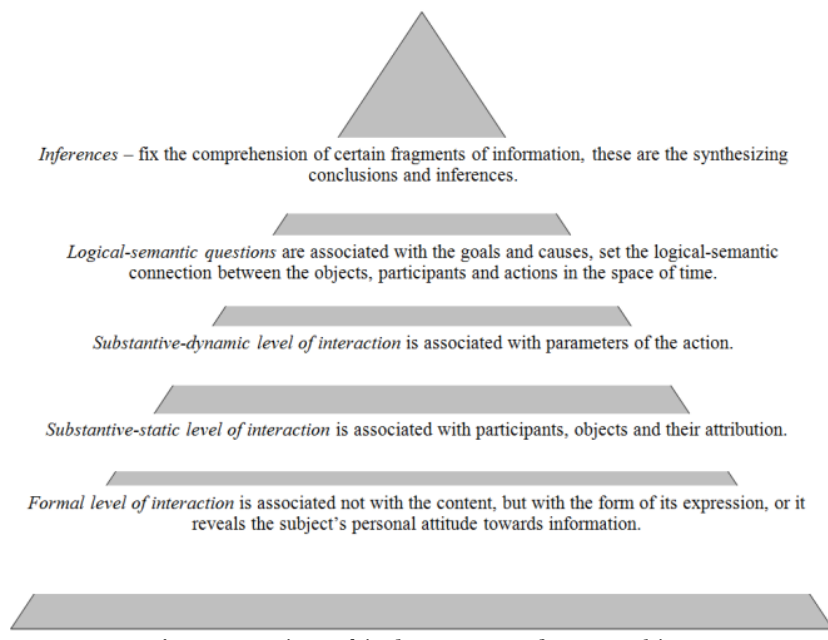

Figure-4. Hierarchical structure of sensemaking.

We have evaluated the ways of distortions by the following criteria: "objectification-subjectification", fullness of description, agency - non-agency (Fairclough, 1992). 
The procedure of processing is briefly represented in the Table 1.

Table-1. The procedure of processing.

\begin{tabular}{l|l}
\hline \multicolumn{1}{c}{ Stages } & \multicolumn{1}{c}{ Criteria } \\
\hline $\mathbf{1}^{\text {st }}$ stage & $\begin{array}{l}\text { Organizational order (by the key words or phrases in } \\
\text { interview). } \\
\text { Discourse-analysis of the narratives of } \\
\text { interpretations, reconstruction of the }\end{array}$
\end{tabular}
general discourse.

Reconstruction (on the basis of semantic proximity) of the kinds of discourses that reflect discourse-order of the behavior in organization.

Acceptance/avoidance of responsibility (by the construction of the sentence, presence or absence of the agent of action).

Categoricity/uncertainty about certain way of behavior (by the modality of utterances).

Basic themes of the discourse (by the thematic proximity of the main topics of interview).

Formal-external forms of behavior.

Static-elements and characteristics.

Dynamic - ways of action and technologies.

Logical-semantic-purposes, reasons, grounds.

Inferences - values and beliefs.

$3^{\text {rd }}$ stage

Evaluation of the way of distortions discourses.

\section{Discussion of the Results}

With the help of discourse-analysis and through applying hierarchical model of sensemaking we obtained 3 main kinds of discourse: formal discourses (20\%), static discourses (60\%) and dynamic discourses (20\%). On the logical-semantic level and on the level of inferences we haven't discovered any kinds of discourse.

In the Table 2 we have presented the kinds of discourses.

Table-2. The results of processing. Kinds of discourses.

\begin{tabular}{|c|c|c|c|}
\hline $\begin{array}{ll}\text { Kinds } & \text { of } \\
\text { discourses }\end{array}$ & Procedural style & Personal-authoritarian style & Participative style \\
\hline $\begin{array}{l}\text { Hierarchical } \\
\text { levels }\end{array}$ & Formal level $(20 \%)$ & Static level $(60 \%)$ & Dynamic level (20\%) \\
\hline \multicolumn{4}{|l|}{$\begin{array}{l}\text { Parameters of } \\
\text { classification }\end{array}$} \\
\hline $\begin{array}{l}\text { Organizational } \\
\text { order }\end{array}$ & $\begin{array}{l}\text { 1."Job descriptions" are } \\
\text { responsible for the } \\
\text { organization's effectiveness. } \\
\text { 2. Strict subordination. } \\
\text { 3. Implementation practice } \\
\text { towards the instructions. }\end{array}$ & $\begin{array}{ll}\text { 1. Submission } & \text { to the } \\
\text { direct orders. } & \\
2 . \quad \text { Discipline } & \text { towards } \\
\text { managers. } & \end{array}$ & $\begin{array}{l}\text { 1. Mutual } \\
\text { understanding and } \\
\text { agreement between people. } \\
2 \text { Allocation of duties } \\
\text { through negotiations. } \\
3 . \quad \text { Adherence to the } \\
\text { unwritten laws of the team. } \\
4 \text { Agreements are } \\
\text { responsible for the } \\
\text { effectiveness } \\
\text { organization. }\end{array}$ \\
\hline Manager & $\begin{array}{l}\text { 1. Is able to properly } \\
\text { position himself, to affirm } \\
\text { the power. } \\
\text { 2. Protects the status of } \\
\text { managers }\end{array}$ & $\begin{array}{l}\text { 1. Is the main guarantor and } \\
\text { the reason for the effectiveness. } \\
2 \text {. Strong, attractive } \\
\text { personality. } \\
\text { 3. Sets the goals alone, enjoys } \\
\text { absolute authority and power. } \\
\text { 4. Regulates relations and } \\
\text { conflicts between the }\end{array}$ & $\begin{array}{l}\text { 1.Consultant, provides the } \\
\text { subordinates with support. } \\
\text { 2. Consults. when making } \\
\text { decisions } \\
\text { 3. Doesn't interfere with } \\
\text { conflicts. }\end{array}$ \\
\hline
\end{tabular}




\begin{tabular}{|c|c|c|c|}
\hline & & $\begin{array}{l}\text { subordinates. } \\
\text { 5. Sets the requirement to the } \\
\text { personnel, achieves their } \\
\text { realization, teaches. }\end{array}$ & \\
\hline Personnel & $\begin{array}{l}\text { 1. Observe } \\
\text { implementation standards. } \\
2 . \quad \text { Don't breach the } \\
\text { instructions. } \\
\text { 3. Don't violate the } \\
\text { manager's status. }\end{array}$ & $\begin{array}{l}\text { 1.Submit to the orders, prove } \\
\text { manager's significance and } \\
\text { loyalty to him. } \\
\text { 2. Demonstrate obedience, } \\
\text { discipline, loyalty, fully accept } \\
\text { manager's power (or compete } \\
\text { with him). } \\
\text { 3. Address to the manager to } \\
\text { get the help or attention. }\end{array}$ & $\begin{array}{l}\text { 1. Negotiate with } \\
\text { each other. } \\
2 . \quad \text { Solve the conflict } \\
\text { without manager's } \\
\text { involvement. } \\
\text { 3. Respect the } \\
\text { authority of the senior } \\
\text { manager. }\end{array}$ \\
\hline Intentions & $\begin{array}{l}\text { 1.Preserving the established } \\
\text { order and manager's } \\
\text { position. } \\
\text { 2. Safety. }\end{array}$ & $\begin{array}{l}\text { 1.Preserving the manager's } \\
\text { power. } \\
\text { 2. Self-affirmation. }\end{array}$ & 1. Affiliation, acceptance. \\
\hline
\end{tabular}

We have discovered several styles of distortions (informational corruption).

Procedural style (formal level).

Manager - protects formal status, not agentive.

Personnel-oriented towards discipline, not agentive.

Participants' basic motive - safety.

Organizational order - subordination and adherence to the instructions.

The reason for effectiveness in organization - correct instructions, formal adherence to the rules.

Authoritarian style (static level).

Manager - the main reason for the effectiveness in organization, manages the organization alone, requires submission, agentive.

Personnel-demonstrate loyalty, submission and respect towards manager, oriented towards discipline, not agentive.

Participants' basic motive-self-affirmation, power.

Organizational order - execution of management's orders, similar to the "army".

The reason for effectiveness in organization - the manager's personal qualities.

"Participative style” (dynamic level).

Manager is a consultant, advisor, not agentive.

Personnel follow internal arrangements, not agentive.

Participants' basic motive - affiliation, acceptance.

Organizational order - observance of the internal arrangements, allocation of duties through negotiations.

The reason for effectiveness in organization is the quality and adherence to the internal arrangements.

We have discovered the following phenomena - ways of distortions.

\subsection{Value Orientation}

Discursive descriptions of organization don't include the goals, reasons, grounds (logical-semantic level) as well as mission, company's usefulness in the market, the desired ultimate condition in organization, beliefs, concept (the level of inferences). Hypothetically supposed logical-semantic discourse and the discourse of inferences were absolutely absent. Organization's value and usefulness were ignored.

\subsection{Responsibility}

Managers erroneously make themselves guilty for the existent situation or, on the contrary, deny the responsibility and their involvement with the problem. Real responsibility is usually reduced to the one element: either to certain formal rules, or to the manager, or to the personnel. In formal discourse we have discovered non-personified agentivity - formal rules are responsible for the people's behavior. Non-agentivity leads to self- justification, distancing form problems, failure avoidance, absence of initiative and real organizational changes.

\subsection{Narrow-Mindedness}

Managers are concentrated on themselves and on the relationships "manager-personnel", they isolate themselves from the external environment (from the product, clients, market).

The styles of sensemaking reduce the amount of variables, discourses are reduced to the level that the participants can understand, observe and control by themselves. This decreases adaptational possibilities of organization. 
Thus we have found evident distortions and transformations of meaning and the fact of producing subjective ideology that justifies the state of affairs by the ineffective people or relationships. Managers compete with the company's owner to produce the meaning of organization. This allows managers to avoid objective economic responsibility for their own actions and for the established state of affairs.

\section{Conclusions and Perspectives}

\subsection{As a Result, Let's Make the Main Conclusions}

In a crisis transitional environment and ideology forms in organizations that reduces the morphology, distorts elements, emphases, initiator's concept" defensive behavior of displacement arises.

The initiator's initial concept loses its symbolic value and can't be realized.

Managers avoid to produce and transmit meanings, refuse to reduce uncertainty. They reduce the pressure of responsibility with the help of ideology, creating the discourse that justifies such behavior. The function of ideology is to simplify, depersonify and to reduce the need for the productive tension. So they start to compete with initiator for the meaning, in such a way creating organizational myth.

In a transitional crisis environment the process of sensemaking is not normative, non-standard, it is rather individual, not mass one; it is fixed on the level of individual person, not on the level of the general principles in the society. In a situation of the rise of uncertainty, appearance of a great amount of parameters, dynamics and in the absence of economic culture this level of organizational discourse falls. Of course, all this prevents the survival of organization in a crisis uncertain environment.

In a situation of the uncertainty the producing of meanings is needed on a certain level of hierarchy (on the level of mission, goals). And we have empirically proved that the workers distort them. That is why during organizational changes there is a special pressure for the recovery of the sensemaking process.

Consequently, official organizational policy must first of all be oriented towards transformation of ideology into methodology of solving organizational problems.

Ideology is an unproductive way of sensemaking in uncertain situation in which there is a lack of formalization. It arises where there is lack of formalization and control - on the highest level of organization.

\section{References}

Choulioraki, L., \& Fairclough, N. (1999). Discourse on late modernity: Edinberg University Press.

Fairclough, N. (1992). Discourse and social change (pp. 272). UK: Polity Press.

Jorgensen, M. V., \& Phillips, L. J. (n.d). Discourse-analysis. Theory and method. Transl. from Rnglish by Kiseleva, A.A (2nd ed., pp. 352). Kharkov: Publishing House "Humanitarian Center".

Kiseleva, A. A. (2004). Communication on organizations. Kiseleva, A.A//Oganizational psychology//ed. By Vlasov, P.K., Manichev, S.A., Sukhdolsly, G.V. - Saint-Petersburg: Publishing house of Saint-Petersburg State University (pp. 76-89). Kharkov: Publishing House "Humanitarian Center".

Laclau, E., \& Mouff, C. (1985). Hegemony and socialist strategy: Towards a radical democratic polotics (pp. 240). London: Verso.

Schank, R. (1985). Inferences in text processing: Cambridge University Press.

Vlasov, P. K. (2004). Psychology of organizational concept (pp. 288). Kharkov: Humanitarian Center.

Weik, K. (2001). Making sense in organisations (pp. 483). UK: Blackwell Publishing.

Zankovsky, A. N. (2011). Psychology of leadership (pp. 296). Moscow: Institute of Psychology of the Russian Academy of Sciences. 